\title{
Recurrent alterations of the WW domain containing oxidoreductase gene spanning the common fragile site FRA16D in multiple myeloma and monoclonal gammopathy of undetermined significance
}

\author{
HIROSHI HANDA $^{1 *}$, YOSHIKO SASAKI ${ }^{2 *}$, HIKARU HATTORI ${ }^{2}$, LOBNA ALKEBSI $^{2}$, \\ TETSUHIRO KASAMATSU ${ }^{2}$, TAKAYUKI SAITOH ${ }^{2}$, TAKEKI MITSUI ${ }^{1}$, AKIHIKO YOKOHAMA $^{3}$, \\ NORIFUMI TSUKAMOTO ${ }^{4}$, MORIO MATSUMOTO ${ }^{5}$ and HIROKAZU MURAKAMI ${ }^{2}$
}

\begin{abstract}
Departments of ${ }^{1}$ Medicine and Clinical Science, and ${ }^{2}$ Laboratory Science, Gunma University Graduate School of Medicine; ${ }^{3}$ Blood Transfusion Service and ${ }^{4}$ Oncology Center, Gunma University Hospital, Maebashi, Gunma 371-8511; ${ }^{5}$ Department of Hematology, National Hospital Organization Shibukawa Medical Center, Shibukawa, Gunma 377-0280, Japan
\end{abstract}

Received September 20, 2016; Accepted March 3, 2017

DOI: $10.3892 / \mathrm{ol} .2017 .6672$

\begin{abstract}
The putative tumor suppressor gene WW domain containing oxidoreductase (WWOX) spans a common fragile site (CFS) on chromosome 16q23.3. CFSs are regions of profound genomic instability and sites for genomic deletions in cancer cells. Therefore, WWOX is structurally altered in diverse nonhematological cancer types. However, the function of WWOX in hematological tumor types, including multiple myeloma (MM) and monoclonal gammopathy of undetermined significance (MGUS) remains unclear. WWOX expression and methylation in patients with MM, MGUS, or noninvasive lymphoma (control) were analyzed using reverse transcriptionand methylation specific-polymerase chain reaction analysis. Variant WWOX transcripts were detected in 65 and $50 \%$ of patients with MM and MGUS, respectively, compared with $10 \%$ of controls. WWOX expression was higher in patients with MM, and WWOX promoter methylation was detected in $35 \%$ of patients with MM compared with $5 \%$ of patients with MGUS and $4 \%$ of controls. WWOX promoter methylation was significantly associated with shorter overall survival time of patients, in particular those with MM who were never treated with novel agents. Genomic alterations, including deletions and promoter methylation that affect WWOX expression occur
\end{abstract}

Correspondence to: Dr Hiroshi Handa, Department of Medicine and Clinical Science, Gunma University Graduate School of Medicine, 3-39-22 Showa-machi, Maebashi, Gunma 371-8511, Japan E-mail: handahiroshi@gunma-u.ac.jp

*Contributed equally

Key words: multiple myeloma, monoclonal gammopathy of undetermined significance, $\mathrm{WW}$ domain containing oxidoreductase gene, common fragile site, methylation early and may be involved in the pathogenesis, progression, and prognosis of MM.

\section{Introduction}

The underlying molecular mechanism of multiple myeloma (MM) is associated with oncogene activation caused by the translocation of the immunoglobulin heavy chain gene $(1,2)$. Mutations or deletions of certain genes are also involved $(3,4)$. Although $\mathrm{MM}$ is incurable, the median survival time is currently 5-7 years compared with 3 years before 2000 due to the development of novel therapies (5). The prognosis of patients with MM is associated with genetic abnormalities (3), and the identification of molecular genetic markers for predicting prognosis is therefore essential. The application of high-throughput next-generation sequencing techniques has contributed to efforts to understanding the pathogenesis of MM $(3,4)$; however, full coverage of the genomic alterations involved remains unclear.

Chromosomal instability is a feature of certain cancer types and is associated with the presence of chromosomal fragile sites (CFSs) (6). Common fragile sites are present in normal chromosomes, and are prone to forming chromosomal gaps and breaks under conditions that partially inhibit DNA synthesis (7). Furthermore, CFSs are regions of profound genomic instability and are frequent sites for deletions and other alterations in cancer cells $(8,9)$. Fragile site aphidicolin type common fragile site (16) (q23.2) (FRA16D) on chromosome $16 \mathrm{q} 23.2$ is the second most frequently expressed CFS region (10) and has been identified as deleted in multiple types of cancer (11-13).

The WW domain containing oxidoreductase (WWOX) gene was identified as a putative tumor suppressor gene (14-17) and spans FRA16D $(16,18,19)$. Genomic alterations, including homozygous and hemizygous deletions that affect the WWOX locus, occur in certain types of cancer (20-22). Deletion of all or part of chromosome $16 \mathrm{q}$ and loss of heterozygosity 
occurs in patients with MM (23-25). In addition, relatively low expression levels of WWOX and the cylindromatosis gene, which reside on chromosome 16q, have been associated with worse prognosis (24).

WWOX is the target of recurrent deletions of chromosome $16 \mathrm{q}(15-17,19)$ that disrupt one WWOX allele by removing exons 6-8 that encode the oxidoreductase domain, leading to the production of variant transcripts. WWOX variant transcripts are frequently identified in breast, lung, esophageal and hematological malignancies (17,26-30).

There is evidence to indicate that the loss of full length WWOX expression is due to the localization of WWOX at one of the most active human CFSs $(15-17,19)$; however, other studies have demonstrated that the methylation of the WWOX promoter leads to decreased expression (31-33). Furthermore, epigenetic processes, particularly DNA methylation, are involved in carcinogenesis, and multiple studies have reported an association between the methylation of tumor suppressor genes and poor prognosis of patients with MM (34-40).

Genes with CFSs are often methylated in various types of malignancy $(41,42)$, but little information is available regarding hematologic malignancy types $(43,44)$. In addition, the methylation of the WWOX promoter has been associated with worse prognosis of patients with different types of cancer $(31,45-47)$. To the best of our knowledge, no previous studies have reported an association between alterations of WWOX and progression of MM. The present study aimed to elucidate the function of WWOX in the pathogenesis of MM.

\section{Materials and methods}

Cell lines. The human myeloma cell line RPMI8226 was obtained from the American Type Culture Collection (Manassas, VA, USA), and KMS11, KMS12PE, KMM1, KMS18, and KMS26 human myeloma cell lines were provided by Dr Takemi Otsuki (Kawasaki Medical School, Okayama, Japan). The cell lines were cultured in $10 \mathrm{ml}$ RPMI-1640 medium (Sigma-Aldrich; Merck KGaA, Darmstadt, Germany) supplemented with $10 \%$ fetal bovine serum (Thermo Fisher Scientific, Inc., Waltham, MA, USA) at $37^{\circ} \mathrm{C}$ in an atmosphere containing $5 \% \mathrm{CO}_{2}$.

Patients. Subjects included 165 patients with MM (82 male and 83 female) and an average age of 67 (range 34-87), 33 patients (16 male and 17 female) with monoclonal gammopathy of undetermined significance (MGUS) with an average age of 67 (range 44-81), diagnosed according to International Myeloma Working Group (IMWG) Criteria for the Diagnosis of Multiple Myeloma (48) and 25 patients with lymphoma lacking infiltration of the bone marrow as a control. All patients were treated at Gunma University Hospital between January 2004 and September 2011. The present study was approved by the Institutional Review Board of Gunma University Hospital (IRB no. 810). Written informed consent was obtained from all patients prior to $3 \mathrm{ml}$ of bone marrow aspirate collection.

Plasma cell purification. The plasma cells were purified from BM mononuclear cells from $30 \mathrm{MM}$ patients using anti-CD138 antibody conjugated with PE (Beckman-Coulter, Brea, CA) and Easy Sep PE positive selection containing
anti-PE antibody conjugated with micro-magnetic beads kit (STEMCELL Technologies, Vancouver, BC, Canada). The purity of the CD138 positive plasma cells was analyzed using a flow cytometer (FACSCanto II, Becton Dickinson, San Jose, CA, USA).

Isolation of nucleic acids. DNA was extracted from 88 patients with MM using QIAamp DNA Blood Midi kit (Qiagen, Inc., Valencia, CA, USA), according to the manufacturer's protocol. DNA and RNA were extracted from 77 patients with MM and 33 patients with MGUS and 25 patients with lymphoma lacking infiltration of the bone marrow, respectively, using an All-Prep mini-kit (Qiagen, Inc.) according to the manufacturer's protocol.

Nested reverse transcription-polymerase chain reaction (RT-PCR) analysis of WWOX transcripts. cDNA was synthesized from $10 \mathrm{ng}$ total RNA obtained from 77 patients with MM, 33 patients with MGUS and 25 control patients, and cell lines KMM1, KMS11, KMS12PE, KMS18, KMS26 and RPMI8226 using a PrimeScript RT-PCR kit with gDNA Eraser (Takara Bio, Inc., Otsu, Japan). The first and second PCR amplifications were performed using the nested primers as follows: First forward, 5'-AGTTCCTGAGCGAGTGGA CC-3' and reverse, 5'-TTACTTTCAAACAGGCCACCAC-3' and second forward, 5'-AGGTGCCTCCACAGTC-3' and reverse, 5'-GTGTGTGCCCATCCGCTCT-3' (29,30). Each reaction $(50 \mu \mathrm{l}$ each) contained $0.2 \mu \mathrm{mol}$ of each primer, $2.0 \mathrm{mM} \mathrm{MgCl}, 0.2 \mathrm{mM}$ dNTP mix, 1X PCR buffer and 1.25 units of Takara ExTaq Hot Start Version (Takara Bio, Inc.). The thermocycling conditions maintained were as follows: $95^{\circ} \mathrm{C}$ for $8 \mathrm{~min} ; 35$ cycles at $94^{\circ} \mathrm{C}$ for $30 \mathrm{sec}, 57^{\circ} \mathrm{C}$ for $30 \mathrm{sec}$, and $72^{\circ} \mathrm{C}$ for $1 \mathrm{~min}$; and an extension step at $72^{\circ} \mathrm{C}$ for $5 \mathrm{~min}$. A total of $1 \mu \mathrm{l}$ amplification product from the first reaction was used for the second reaction. The amplicons were electrophoresed through a $2 \%$ agarose gel and visualized using ethidium bromide.

Methylation-specific PCR (MSP). The CpG island of the WWOX gene is located $406 \mathrm{bp}$ upstream of the transcription start site and is considered the promoter region. MSP was used to detect the methylation levels of this region. DNA obtained from 165 patients with MM, 33 patients with MGUS and 25 control patients, and cell lines KMM1, KMS11, KMS12PE, KMS18, KMS26 and RPMI8226 were used for the MSP analysis. Each $0.5 \mu \mathrm{g}$ sample of genomic DNA was treated with sodium bisulfite using the MethylEasy Xceed Rapid DNA Bisulfite Modification kit (Takara Bio, Inc.) following manufacturer's protocol, and the converted DNA was subjected to PCR. MSP was performed using specific primers designed to amplify methylated or unmethylated sequences of the WWOX promoter. The primer sequences for methylated or unmethylated DNA are as follows: Methylated forward, 5'-TATGGG CGTCGTTTTTTTAGTT-3' and reverse, 5'-CAATCTCCG CAATATCGCGACA-3'; unmethylated forward, 5'-TAT GGGTGTTGTTTTTTTAGTT-3' and reverse, 5'-CAATCT CCACAATATCACAACA-3' (31). Each reaction (20 $\mu \mathrm{l}$ each) contained $0.2 \mu \mathrm{mol}$ of each primer, $2.0 \mathrm{mM} \mathrm{MgCl}, 0.2 \mathrm{mM}$ dNTP mix, 1X PCR buffer and 1.25 units of Takara ExTaq Hot Start Version (Takara Bio, Inc.). The thermocycling conditions 
maintained were as follows: $95^{\circ} \mathrm{C}$ for $8 \mathrm{~min} ; 35$ cycles at $94^{\circ} \mathrm{C}$ for $30 \mathrm{sec}, 58^{\circ} \mathrm{C}$ for $30 \mathrm{sec}$, and $72^{\circ} \mathrm{C}$ for $1 \mathrm{~min}$; and an extension step of $72^{\circ} \mathrm{C}$ for $5 \mathrm{~min}$. The amplicons were electrophoresed through a $2 \%$ agarose gel and visualized using ethidium bromide.

Statistical analysis. IBM SPSS software (version 22.0; IBM SPSS, Armonk, NY, USA) was used for statistical analysis. Frequencies were compared using the $\chi^{2}$ test, and mean values were compared using the Student's t-test or the Mann-Whitney $\mathrm{U}$ test. Overall survival (OS) and statistical significance were calculated using the Kaplan-Meier estimator method, log-rank test, and generalized Wilcoxon test.

\section{Results}

Analysis of WWOX mRNAs. Nested PCR assays (Fig. 1A) detected the full-length wild-type WWOX mRNA and a short variant WWOX mRNA lacking exons 6-8. The variant type was expressed at low levels by KMM1 and KMS18 cells, and at higher levels by KMS11 and RPMI8226 cells. Full-length wild-type WWOX was detected in KMS12PE and KMS26 cells, and RPMI8226 cells expressed the wild-type and variant transcripts.

WWOX transcripts were undetectable in 9 patients with MM, 7 patients with MGUS and 4 patients with lymphoma (data not shown), and those patients were excluded from the following analysis. The variant WWOX mRNA was detected in 44/68 (65\%) patients with MM (Fig. 1B), 13/26 (50\%) cases of patients with MGUS and in 2/21 (10\%) patients with lymphoma (Table I). This indicated that MM and MGUS bone marrow cells expressed the variant WWOX at a similar frequency $(\mathrm{P}=0.16)$, and at a significantly higher frequency compared with lymphoma bone marrow cells $(\mathrm{P}<0.001$ and $\mathrm{P}=0.004$, respectively; Table I). The similar high frequencies of detection of variant WWOX mRNA in patients with MM and MGUS suggested that WWOX alteration occurred during the premalignant stage of MM.

CD138-positive plasma cells and CD138-negative bone marrow cells obtained from the same patients with MM were purified and analyzed to determine whether variant WWOX was expressed by plasma cells. The variant WWOX mRNA was detected in the CD138-positive plasma cells of $17 / 30$ patients (57\%), which was equivalent to the results of the analysis of whole-marrow mononuclear cells of patients with $\mathrm{MM}$ described above ( $\mathrm{P}=0.45$; data not shown). This was significantly higher compared with the detection in $6 / 30$ (24\%) of the CD138-negative cell samples $(\mathrm{P}=0.01)$. These results indicated that the variant form of WWOX mRNA was a genuine abnormality of MM cells and not a characteristic of all hematopoietic cells.

Methylation of the WWOX promoter in MM cell lines and tumor cells. MSP analysis detected WWOX promoter methylation in 2/6 (KMM1 and KMS18) cell lines (Fig. 2A) and in $3 / 4$ patients with MM (Fig. 2B). Methylation of the WWOX promoter was detected in samples from 58/165 (35\%) patients with MM, 2/33 (6\%) patients with MGUS, and in 1/25 patients with lymphoma (4\%). The frequency of WWOX promoter methylation in patients with MM was significantly higher

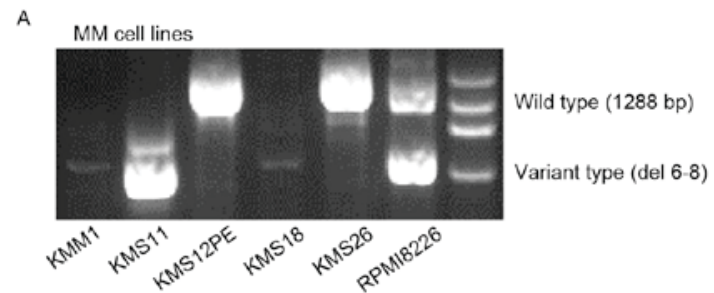

B

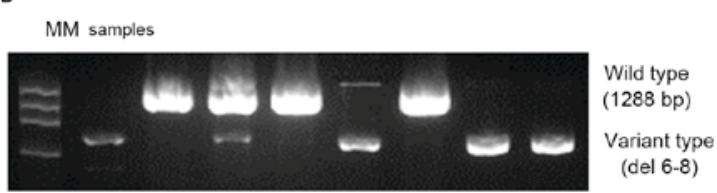

Figure 1. Detection of wild-type and variant WWOX mRNAs using nested reverse transcription-polymerase chain reaction. (A) The wild-type WWOX and variant amplicons migrated as 1,288 and 600 bp bands, respectively. The variant WWOX amplicon was detected in the KMM1, KMS11, KMS18 and RPMI8226 cell lines, and RPMI8226 cells expressed both forms. A weak band was detected in KMM1 and KMS18 cells, in which the WWOX promoter was methylated. (B) Detection of wild-type and variant WWOX amplicons in the plasma cells of patients with MM. WWOX, WW domain containing oxidoreductase; bp, base pairs; MM, multiple myeloma.

A MM cell lines
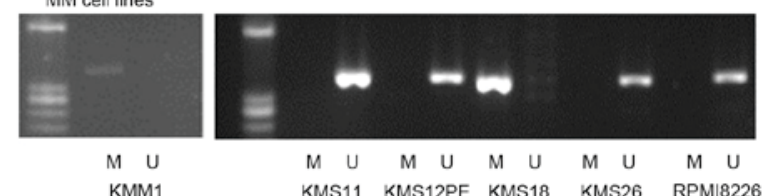

KMM

KMS11 KMS12PE KMS18 KMS26 RPMI8226

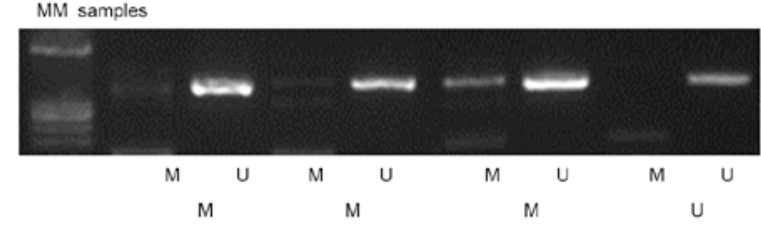

Figure 2. Methylation-specific polymerase chain reaction analysis of the WWOX promoter. (A) Lane M, methylated WWOX promoter; Lane U, unmethylated WWOX promoter. WWOX promoter methylation was detected in the DNA of the KMM1 and KMS18 cell lines. (B) Methylated and unmethylated WWOX promoter DNA of patients with MM was detected. WWOX, WW domain containing oxidoreductase; MM, multiple myeloma.

compared with those with MGUS $(\mathrm{P}=0.001)$ or lymphoma $(\mathrm{P}=0.002)$, but the difference was not significant between patients with MGUS or lymphoma ( $\mathrm{P}=0.73$; Table I). This indicated that WWOX was preferentially methylated in MM cells.

To determine whether methylation was specific for WWOX or reflected the methylation status of tumor suppressor genes in MM cells, Ras association domain family member 1 isoform A (RASSF1A) promoter methylation was analyzed. RASSF1A promoter methylation was detected in 63/165 patients with MM (38\%), 14/33 patients with MGUS (42\%), and in 3/25 patients with lymphoma (12\%; Table I). No significant difference in the frequency between the number of patients with $\mathrm{MM}$ and MGUS was identified $(\mathrm{P}=0.70)$. In patients with $\mathrm{MM}$, the frequency of RASSF1A promoter methylation was equivalent to that of WWOX hypermethylation. However, the RASSF1A promoter was more frequently methylated compared with WWOX in patients with MGUS ( $\mathrm{P}=0.04$; data not shown), 
Table I. Frequencies of variant WWOX mRNA, WWOX promoter methylation, and RASSF1A promoter methylation in patients with MM or MGUS and control subjects.

\begin{tabular}{lcccr}
\hline & \multicolumn{3}{c}{ No. patients (\%) } \\
\cline { 2 - 4 } Genomic alteration & Lymphoma & MGUS & MM & P-value \\
\hline Variant WWOX & $2 / 21(10)$ & $13 / 26(50)$ & $44 / 68(65)$ & $0.1620^{\mathrm{a}}$ \\
& & & $0.0001^{\mathrm{b}}$ \\
& & & $0.0030^{\mathrm{c}}$ \\
WWOX methylation & $1 / 25(4)$ & $2 / 33(6)$ & $58 / 165(35)$ & $0.0012^{\mathrm{a}}$ \\
& & & & $0.0020^{\mathrm{b}}$ \\
& & & & $0.7300^{\mathrm{c}}$ \\
RASSF1A methylation & & & $0.7120^{\mathrm{a}}$ \\
& & & & $0.0120^{\mathrm{b}}$ \\
& & & & $0.0190^{\mathrm{c}}$
\end{tabular}

${ }^{a}$ MM vs. MGUS; ${ }^{b} M M$ vs. lymphoma; ${ }^{c}$ MGUS vs. lymphoma. WWOX, WW domain containing oxidoreductase; MM, multiple myeloma; MGUS, monoclonal gammopathy of undetermined significance; RASSF1A, Ras association domain family member 1 isoform A.

A

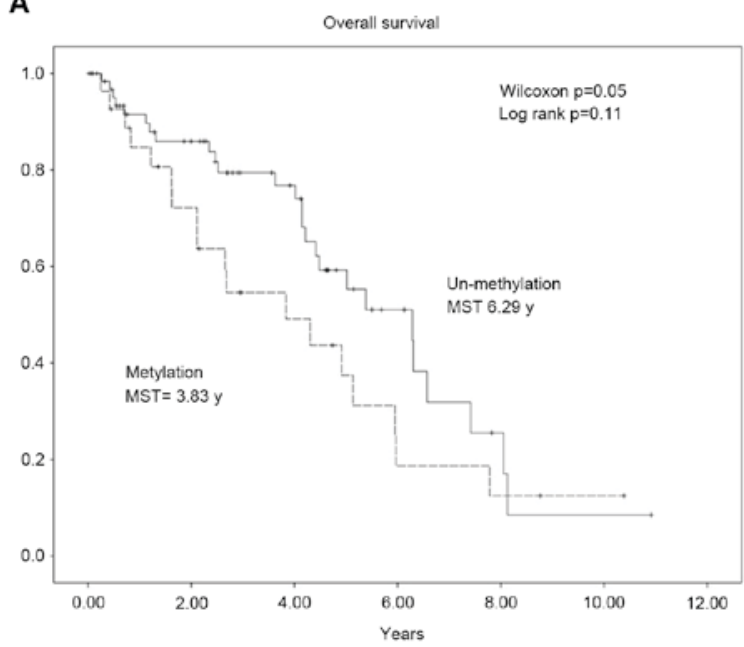

B

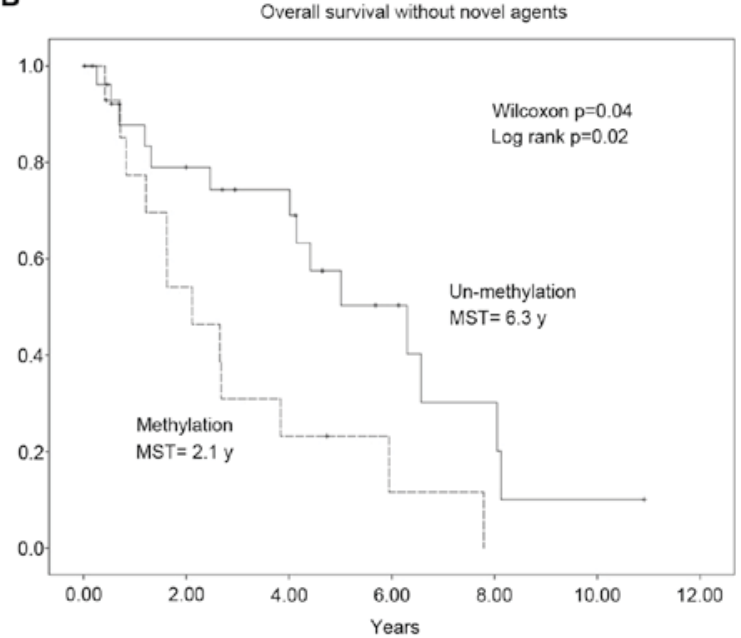

Figure 3. Analyses of OS and WWOX promoter methylation. The solid and dashed lines represent the OS of patients with or without WWOX promoter methylation, respectively. (A) Kaplan-Meier analysis of patients with and without WWOX promoter methylation revealed that the median survival times were 3.83 and 6.29 years, respectively. (B) Stratification of patients according to the type of chemotherapy. The median survival times of the patients with and without WWOX promoter methylation were 2.1, and 6.3 years, respectively. OS, overall survival; WWOX, WW domain containing oxidoreductase.

suggesting that specific methylation of WWOX was associated with the progression of MM.

Association between the prognosis of patients with MM and WWOX promoter methylation. The association between WWOX promoter methylation and the OS of patients with MM was determined using the Kaplan-Meier estimator method, log-rank, and the generalized Wilcoxon test. The median OS time was shorter in patients with methylated WWOX sequences compared with those without methylation (3.83 vs. 6.29 years; Fig. 3A). This difference was significant according to the results of the generalized Wilcoxon test $(\mathrm{P}=0.02)$ but not those of the log-rank test $(\mathrm{P}=0.11)$. As novel agents, namely bortezomib, thalidomide and lenalidomide, are effective for treating $\mathrm{MM}$, the patients were stratified according to those treated with or without novel agents and the data were analyzed again. The median OS time of patients with WWOX promoter methylation was shorter compared with those without methylation (2.1 vs. 6.3 years). The difference was significant according to the results of the generalized Wilcoxon test $(\mathrm{P}=0.04)$ and the log-rank test $(\mathrm{P}=0.02$; Fig. $3 \mathrm{~B})$. In contrast, no significant difference between the median OS times of each class of patients treated with novel agents were identified (methylation, 5.1 years; undetectable methylation, 5.4 years; $\mathrm{P}=0.73$; data not shown).

Analysis of WWOX promoter methylation, $\beta 2$-microglobulin levels, and International Staging System (ISS) classification. The higher incidence of WWOX promoter methylation in patients with MM compared with those with MGUS, and 
the association between methylation and shorter OS time, indicated that WWOX promoter methylation was associated with disease progression. To support this hypothesis, the association between WWOX promoter methylation, serum $\beta 2$-microglobulin levels and MM stage was analyzed according to the ISS (49). The mean $\beta 2$-microglobulin level was significantly higher in patients with WWOX promoter methylation compared with those without (6.80 vs. $4.68 \mathrm{mg} / \mathrm{l}$; $\mathrm{P}=0.02$; data not shown). The frequency of patients at ISS stage 3 with WWOX promoter methylation was significantly higher compared with those without methylation $(\mathrm{P}=0.02$; data not shown).

\section{Discussion}

In the present study, recurrent expression of a short form of WWOX mRNA was demonstrated in patients with MM or MGUS. Furthermore, it was revealed that the WWOX promoter was frequently methylated in patients with $\mathrm{MM}$, and that this increased during the progression of disease from MGUS to advanced MM. In addition, WWOX promoter methylation was identified to be associated with a shorter median OS time.

The wild-type transcript is ubiquitously expressed and shorter variants also occur $(15,17)$. For example, homozygous deletion of chromosome 16q23.2 in various cancer cell lines includes deletions of WWOX exons (17) that generate shorter WWOX mRNA variants. In a previous study, numerous truncated WWOX variants lacking exons 5-8 were identified in clinical samples obtained from patients with breast cancer (27). Reduced expression of the full-length WWOX transcript by cancer cells and the detection of high levels of variant WWOX transcripts that occur specifically in tumors indicates that WWOX may be involved in oncogenesis (27).

In the present study, variant WWOX mRNAs were detected in myeloma cell lines and plasma cells of patients with MM or MGUS, but at a significantly lower frequency in the cells of control patients. These results indicated that WWOX alteration was associated with aberrant plasma cells.

The instability of CFSs correlates with genomic instability in precancerous lesions (50) and the early stages of oncogenesis are associated with the DNA damage response $(50,51)$. Genomic instability and abnormalities are hallmarks of MM, and aberrant DNA repair pathways are involved in disease onset and progression (52). WWOX deficiency reduces the levels of ATM serine/threonine kinase and impairs DNA repair, which may drive genomic instability (51). Therefore, WWOX alterations may also cause genomic instability. The results of the present study on variant WWOX mRNA expression in patients with MGUS suggested that the alteration of a CFS indicates genomic instability at an early stage of the disease.

Studies of WWOX protein knockout and hypomorphic mice have demonstrated that a functional defect of WWOX leads to the induction of various types of tumor, including lymphoma and plasmacytoma (53-55). In vitro, WWOX inhibits $\beta$-catenin (56) and suppresses the transcriptional activity of the nuclear factor- $\mathrm{\kappa B}$ (NF- $\mathrm{kB})$-RELA proto-oncogene, NF- $\mathrm{\kappa B}$ subunit complex (57), which are involved in the pathogenesis of MM. Variant WWOX serves as a dominant-negative factor in vitro to inhibit the tumor suppressor function of wild-type
WWOX (26). These findings, taken together with those of the present study, support the hypothesis that the loss of WWOX function serves a causative role in the pathogenesis of MM.

The frequent detection of WWOX promoter methylation in the cells of patients with MM, in contrast to patients with MGUS and the control group, indicates that WWOX promoter methylation is associated with MM progression. This is consistent with findings that WWOX methylation correlates with poor prognosis of patients with ovarian cancer (47), head and neck cancer (58), and chorangiocarcinoma (59).

No significant correlation was identified between WWOX methylation and OS. This result may be due to improved treatment outcomes using novel agents. Therefore, patients were stratified according to the types of therapy they received and prognosis was identified as being worse for patients with WWOX methylation if they had not received treatment with a novel agent, suggesting that WWOX methylation may be associated with resistance to conventional cytotoxic drugs.

In conclusion, the present study demonstrated that WWOX promoter methylation is associated with $\beta 2$-microglobulin levels and ISS, indicating that WWOX methylation contributes to MM progression. Unlike WWOX, the rate of methylated RASSF1A was similar between patients with MGUS and MM. Therefore, the association of WWOX methylation with a more progressive and worse phenotype may not reflect the methylation of tumor suppressor genes.

Genomic instability is a hallmark of the majority of types of cancer, and is potentially involved in oncogenesis and the response to therapy. As WWOX is a putative human tumor suppressor gene, it appears possible that the selection for loss of function driven by fragile site instability is involved in MM progression. Further mechanistic studies are required to determine the role of WWOX and other genes within other CFSs in the pathogenesis of MM.

\section{Acknowledgements}

The present study was supported by the Ministry of Education, Science and Culture, Japan (grant no. 20590556).

\section{References}

1. Bergsagel PL and Kuehl WM: Chromosome translocations in multiple myeloma. Oncogene 20: 5611-5622, 2001.

2. Chesi M and Bergsagel PL: Molecular pathogenesis of multiple myeloma: Basic and clinical updates. Int J Hematol 97: 313-323, 2013.

3. Morgan GJ, Walker BA and Davies FE: The genetic architecture of multiple myeloma. Nat Rev Cancer 12: 335-348, 2012.

4. Egan JB, Shi CX, Tembe W, Christoforides A, Kurdoglu A, Sinari S, Middha S, Asmann Y, Schmidt J, Braggio E, et al: Whole-genome sequencing of multiple myeloma from diagnosis to plasma cell leukemia reveals genomic initiating events, evolution, and clonal tides. Blood 120: 1060-1066, 2012.

5. Vincent Rajkumar S: Multiple myeloma: 2014 Update on diagnosis, risk-stratification and management. Am J Hematol 89: 999-1009, 2014.

6. Dillon LW, Burrow AA and Wang YH: DNA instability at chromosomal fragile sites in cancer. Curr Genomics 11: 326-337, 2010.

7. Glover TW: Common fragile sites. Cancer Lett 232: 4-12, 2006.

8. Gao G and Smith DI: Very large common fragile site genes and their potential role in cancer development. Cell Mol Life Sci 71: 4601-4615, 2014.

9. Debatisse M, Le Tallec B, Letessier A, Dutrillaux B and Brison O: Common fragile sites: Mechanisms of instability revisited. Trends Genet 28: 22-32, 2012. 
10. Sutherland GR and Richards RI: The molecular basis of fragile sites in human chromosomes. Curr Opin Genet Dev 5: 323-327, 1995.

11. Balsara BR, Pei J, De Rienzo A, Simon D, Tosolini A, Lu YY, Shen FM, Fan X, Lin WY, Buetow KH, et al: Human hepatocellular carcinoma is characterized by a highly consistent pattern of genomic imbalances, including frequent loss of 16q23.1-24.1. Genes Chromosomes Cancer 30: 245-253, 2001.

12. Paris PL, Witte JS, Kupelian PA, Levin H, Klein EA, Catalona WJ and Casey G: Identification and fine mapping of a region showing a high frequency of allelic imbalance on chromosome 16q23.2 that corresponds to a prostate cancer susceptibility locus. Cancer Res 60: 3645-3649, 2000

13. Hansen LL, Yilmaz M, Overgaard J, Andersen J and Kruse TA Allelic loss of 16q23.2-24.2 is an independent marker of good prognosis in primary breast cancer. Cancer Res 58: 2166-2169, 1998.

14. O'Keefe LV and Richards RI: Common chromosomal fragile sites and cancer: Focus on FRA16D. Cancer Lett 232: 37-47, 2006.

15. Ried K, Finnis M, Hobson L, Mangelsdorf M, Dayan S, Nancarrow JK, Woollatt E, Kremmidiotis G, Gardner A, Venter D, et al: Common chromosomal fragile site FRA16D sequence: Identification of the FOR gene spanning FRA16D and homozygous deletions and translocation breakpoints in cancer cells. Hum Mol Genet 9: 1651-1663, 2000.

16. Bednarek AK, Laflin KJ, Daniel RL, Liao Q, Hawkins KA and Aldaz CM: WWOX, a novel WW domain-containing protein mapping to human chromosome 16q23.3-24.1, a region frequently affected in breast cancer. Cancer Res 60: 2140-2145, 2000.

17. Paige AJ, Taylor KJ, Taylor C, Hillier SG, Farrington S, Scott D, Porteous DJ, Smyth JF, Gabr H and Watson JE: WWOX: A candidate tumor suppressor gene involved in multiple tumor types. Proc Natl Acad Sci USA 98: 11417-11422, 2001.

18. Ludes-Meyers JH, Bednarek AK, Popescu NC, Bedford M and Aldaz CM: WWOX, the common chromosomal fragile site, FRA16D, cancer gene. Cytogenet Genome Res 100: 101-110, 2003

19. Paige AJ, Taylor KJ, Stewart A, Sgouros JG, Gabra H, Sellar GC, Smyth JF, Porteous DJ and Watson JE: A 700-kb physical map of a region of $16 \mathrm{q} 23.2$ homozygously deleted in multiple cancers and spanning the common fragile site FRA16D. Cancer Res 60: 1690-1697, 2000.

20. Alsop AE, Taylor K, Zhang J, Gabra H, Paige AJ and Edwards PA: Homozygous deletions may be markers of nearby heterozygous mutations: The complex deletion at FRA16D in the HCT116 colon cancer cell line removes exons of WWOX. Genes Chromosomes Cancer 47: 437-447, 2008.

21. Beroukhim R, Mermel CH, Porter D, Wei G, Raychaudhuri S, Donovan J, Barretina J, Boehm JS, Dobson J, Urashima M, et al: The landscape of somatic copy-number alteration across human cancers. Nature 463: 899-905, 2010.

22. Bignell GR, Greenman CD, Davies H, Butler AP, Edkins S, Andrews JM, Buck G, Chen L, Beare D, Latimer C, et al: Signatures of mutation and selection in the cancer genome. Nature 463: 893-898, 2010

23. Krummel KA, Roberts LR, Kawakami M, Glover TW and Smith DI: The characterization of the common fragile site FRA16D and its involvement in multiple myeloma translocations. Genomics 69: 37-46, 2000.

24. Jenner MW, Leone PE, Walker BA, Ross FM, Johnson DC, Gonzalez D, Chiecchio L, Dachs Cabanas E, Dagrada GP Nightingale M, et al: Gene mapping and expression analysis of $16 \mathrm{q}$ loss of heterozygosity identifies WWOX and CYLD as being important in determining clinical outcome in multiple myeloma. Blood 110: 3291-3300, 2007.

25. Agnelli L, Mosca L, Fabris S, Lionetti M, Andronache A Kwee I, Todoerti K, Verdelli D, Battaglia C, Bertoni F, et al: A SNP microarray and FISH-based procedure to detect allelic imbalances in multiple myeloma: An integrated genomics approach reveals a wide gene dosage effect. Genes Chromosomes Cancer 48: 603-614, 2009.

26. Bednarek AK, Keck-Waggoner CL, Daniel RL, Laflin KJ, Bergsagel PL, Kiguchi K, Brenner AJ and Aldaz CM: WWOX, the FRA16D gene, behaves as a suppressor of tumor growth. Cancer Res 61: 8068-8073, 2001.

27. Driouch K, Prydz H, Monese R, Johansen H, Lidereau R and Frengen E: Alternative transcripts of the candidate tumor suppressor gene, WWOX, are expressed at high levels in human breast tumors. Oncogene 21: 1832-1840, 2002.
28. Gourley C, Paige AJ, Taylor KJ, Scott D, Francis NJ, Rush R, Aldaz CM, Smyth JF and Gabra H: WWOX mRNA expression profile in epithelial ovarian cancer supports the role of WWOX variant 1 as a tumour suppressor, although the role of variant 4 remains unclear. Int J Oncol 26: 1681-1689, 2005.

29. Yendamuri S, Kuroki T, Trapasso F, Henry AC, Dumon KR, Huebner K, Williams NN, Kaiser LR and Croce CM: WW domain containing oxidoreductase gene expression is altered in non-small cell lung cancer. Cancer Res 63: 878-881, 2003.

30. Kuroki T, Trapasso F, Shiraishi T, Alder H, Mimori K, Mori M and Croce CM: Genetic alterations of the tumor suppressor gene WWOX in esophageal squamous cell carcinoma. Cancer Res 62 : 2258-2260, 2002

31. Iliopoulos D, Guler G, Han SY, Johnston D, Druck T, McCorkell KA, Palazzo J, McCue PA, Baffa R and Huebner K: Fragile genes as biomarkers: Epigenetic control of WWOX and FHIT in lung, breast and bladder cancer. Oncogene 24: $1625-1633,2005$

32. Iliopoulos D, Fabbri M, Druck T, Qin HR, Han SY and Huebner K: Inhibition of breast cancer cell growth in vitro and in vivo: Effect of restoration of Wwox expression. Clin Cancer Res 13: 268-274, 2007.

33. Cantor JP, Iliopoulos D, Rao AS, Druck T, Semba S, Han SY, McCorkell KA, Lakshman TV, Collins JE, Wachsberger P, et al: Epigenetic modulation of endogenous tumor suppressor expression in lung cancer xenografts suppresses tumorigenicity. Int J Cancer 120: 24-31, 2007.

34. Ng MH, Chung YF, Lo KW, Wickham NW, Lee JC and Huang DP: Frequent hypermethylation of p16 and p15 genes in multiple myeloma. Blood 89: 2500-2506, 1997.

35. Guillerm G, Gyan E, Wolowiec D, Facon T, Avet-Loiseau H, Kuliczkowski K, Bauters F, Fenaux P and Quesnel B: p16 (INK4a) and p15 (INK4b) gene methylations in plasma cells from monoclonal gammopathy of undetermined significance. Blood 98: 244-246, 2001

36. Stanganelli C, Arbelbide J, Fantl DB, Corrado C and Slavutsky I: DNA methylation analysis of tumor suppressor genes in monoclonal gammopathy of undetermined significance. Ann Hematol 89: 191-199, 2010

37. Braggio E, Maiolino A, Gouveia ME, Magalhães R, Souto Filho JT, Garnica M, Nucci M and Renault IZ: Methylation status of nine tumor suppressor genes in multiple myeloma. Int J Hematol 91: 87-96, 2010.

38. Gonzalez M, Mateos MV, García-Sanz R, Balanzategui A, López-Pérez R, Chillón MC, González D, Alaejos I and San Miguel JF: De novo methylation of tumor suppressor gene p16/INK4a is a frequent finding in multiple myeloma patients at diagnosis. Leukemia 14: 183-187, 2000.

39. Heuck CJ, Mehta J, Bhagat T, Gundabolu K, Yu Y, Khan S, Chrysofakis G, Schinke C, Tariman J, Vickrey E, et al: Myeloma is characterized by stage-specific alterations in DNA methylation that occur early during myelomagenesis. J Immunol 190: 2966-2975, 2013

40. Kaiser MF, Johnson DC, Wu P, Walker BA, Brioli A, Mirabella F, Wardell CP, Melchor L, Davies FE and Morgan GJ: Global methylation analysis identifies prognostically important epigenetically inactivated tumor suppressor genes in multiple myeloma. Blood 122: 219-226, 2013.

41. Tanaka H, Shimada Y, Harada H, Shinoda M, Hatooka S, Imamura $\mathrm{M}$ and Ishizaki $\mathrm{K}$ : Methylation of the 5' $\mathrm{CpG}$ island of the FHIT gene is closely associated with transcriptional inactivation in esophageal squamous cell carcinomas. Cancer Res 58: 3429-3434, 1998

42. Zöchbauer-Müller S, Fong KM, Maitra A, Lam S, Geradts J, Ashfaq R, Virmani AK, Milchgrub S, Gazdar AF and Minna JD: 5' CpG island methylation of the FHIT gene is correlated with loss of gene expression in lung and breast cancer. Cancer Res 61: 3581-3585, 2001

43. Ishii H, Vecchione A, Furukawa Y, Sutheesophon K, Han SY, Druck T, Kuroki T, Trapasso F, Nishimura M, Saito Y, et al: Expression of FRA16D/WWOX and FRA3B/FHIT genes in hematopoietic malignancies. Mol Cancer Res 1: 940-947, 2003.

44. Uehara E, Takeuchi S, Tasaka T, Matsuhashi Y, Yang Y, Fujita M, Tamura T, Nagai M and Koeffler HP: Aberrant methylation in promoter-associated $\mathrm{CpG}$ islands of multiple genes in therapy-related leukemia. Int J Oncol 23: 693-696, 2003.

45. Nakayama S, Semba S, Maeda N, Matsushita M, Kuroda Y and Yokozaki H: Hypermethylation-mediated reduction of WWOX expression in intraductal papillary mucinous neoplasms of the pancreas. Br J Cancer 100: 1438-1443, 2009. 
46. Wang X, Chao L, Jin G, Ma G, Zang Y and Sun J: Association between $\mathrm{CpG}$ island methylation of the WWOX gene and its expression in breast cancers. Tumour Biol 30: 8-142, 2009.

47. Yan $\mathrm{H}$ and Sun J: Methylation status of WWOX gene promoter $\mathrm{CpG}$ islands in epithelial ovarian cancer and its clinical significance. Biomed Rep 1: 375-378, 2013.

48. International Myeloma Working Group: Criteria for the classification of monoclonal gammopathies, multiple myeloma and related disorders: A report of the International Myeloma Working Group. Br J Haematol 121: 749-757, 2003.

49. Greipp PR, San Miguel J, Durie BG, Crowley JJ, Barlogie B, Bladé J, Boccadoro M, Child JA, Avet-Loiseau H, Kyle RA, et al: International staging system for multiple myeloma. J Clin Oncol 23: 3412-3420, 2005

50. Le Tallec B, Koundrioukoff S, Wilhelm T, Letessier A, Brison O and Debatisse M: Updating the mechanisms of common fragile site instability: How to reconcile the different views? Cell Mol Life Sci 71: 4489-4494, 2014.

51. Abu-Odeh M, Salah Z, Herbel C, Hofmann TG and Aqeilan RI: WWOX, the common fragile site FRA16D gene product, regulates ATM activation and the DNA damage response. Proc Natl Acad Sci USA 111: E4716-E4725, 2014.

52. Gourzones-Dmitriev C, Kassambara A, Sahota S, Rème T, Moreaux J, Bourquard P, Hose D, Pasero P, Constantinou A and Klein B: DNA repair pathways in human multiple myeloma: Role in oncogenesis and potential targets for treatment. Cell Cycle 12: 2760-2773, 2013

53. Aqeilan RI, Trapasso F, Hussain S, Costinean S, Marshall D, Pekarsky Y, Hagan JP, Zanesi N, Kaou M, Stein GS, et al: Targeted deletion of Wwox reveals a tumor suppressor function. Proc Natl Acad Sci USA 104: 3949-3954, 2007.
54. Ludes-Meyers JH, Kil H, Nuñez MI, Conti CJ,Parker-Thornburg J, Bedford MT and Aldaz CM: WWOX hypomorphic mice display a higher incidence of B-cell lymphomas and develop testicular atrophy. Genes Chromosomes Cancer 46: 1129-1136, 2007.

55. Ludes-Meyers JH, Kil H, Parker-Thornburg J, Kusewitt DF, Bedford MT and Aldaz CM: Generation and characterization of mice carrying a conditional allele of the Wwox tumor suppressor gene. PloS One 4: e7775, 2009.

56. Bouteille N, Driouch K, Hage PE, Sin S, Formstecher E, Camonis J, Lidereau R and Lallemand F: Inhibition of the Wnt/beta-catenin pathway by the WWOX tumor suppressor protein. Oncogene 28: 2569-2580, 2009.

57. Fu J, Qu Z, Yan P, Ishikawa C, Aqeilan RI, Rabson AB and Xiao G: The tumor suppressor gene WWOX links the canonical and noncanonical NF- $\kappa$ B pathways in HTLV-I Tax-mediated tumorigenesis. Blood 117: 1652-1661, 2011.

58. Ekizoglu S, Bulut P, Karaman E, Kilic E and Buyru N: Epigenetic and genetic alterations affect the WWOX gene in head and neck squamous cell carcinoma. PloS One 10: e0115353, 2015.

59. Huang C, Tian Y, Peng R, Zhang C, Wang D, Han S, Jiao C, Wang X,Zhang H, Wang Y and Li X: Association of downregulation of WWOX with poor prognosis in patients with intrahepatic cholangiocarcinoma after curative resection. J Gastroenterol Hepatol 30: 421-433, 2015. 